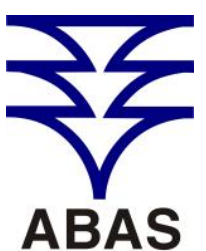

ASSOCIACAO BRASILEIRADE
AGUAS SUBTERRANEAS www.abas.org

\section{ASPECTOS HIDROGEOLÓGICOS DE UM SETOR RURAL NOS MUNICÍPIOS DE ASSÚ E CARNAUBAIS/RN}

\section{HYDROGEOLOGICAL ASPECTS OF A RURAL SECTOR IN ASSÚ AND CARNAUBAIS COUNTIES/RN}

\author{
José Braz Diniz Filho', Paula Stein², Germano Melo Júnior³, \\ Narendra Kumar Srivastava ${ }^{4}$
}

Artigo recebido em: 08/02/2014 e aceito para publicação em: 23/08/2014.

\begin{abstract}
The present work aimed at a hydrostratigraphic characterization in an area about $130 \mathrm{~km}^{2}$, located between Assu/RN and Cranaubais/RN counties, focusing on gathering information to improve utilization of its groundwaters for punctual hydric demands in rural domains. Methodology of study consisted in recording information of wells in the selected sector and in the implementation of an exploratory drilling carried out with percussive technique. In this stage, stratigraphic data and measurements of water levels and electrical conductivity in wells were collected. Ancient alluvial deposits of quaternary age were characterized in the studied area, underlain by carbonatic rocks of the cretaceous Jandaira Formation. Some sectors of this Formation are devoid of alluvial covers and hence the limestones of the Jandaira Formation crop out. Ancient alluvial deposits originate what was called in this study as Alluvial Aquifer I, whereas the Jandaira Formation is equivalent to the homonymous aquifer. The Alluvial Aquifer I, with $64.0 \mathrm{~m}$ maximum thickness in the studied area, develops saturated thickness in restricted sectors of the area, and in these sectors it has a hydraulic interconnection with the Jandaira Aquifer. In fact, the Alluvial Aquifer I acts mostly as a reception and transference/recharge unit for rainwaters toward the underlying Jandaira Aquifer. The Jandaira Aquifer is karstic-fissural in nature, being mainly made up of pure and arenaceous limestones, with interspersed argillites and marls. The studied wells along the referred aquifer reach $122.0 \mathrm{~m}$ maximum depth. Groundwater flow in this aquifer coincides with the overall terrain declivity, from west to east (toward the Rio Açu valley). The potentiometric surface is clearly defined by and probably associated with the occurrence of karstic conducts closely interconnected. Waters of the Jandaira Aquifer in the studied area are fresh to slightly brackish. About $71 \%$ of the evaluated water presented total dissolved solids under $1000 \mathrm{mg} / \mathrm{L}$, therefore below the maximum permitted standard value of potability for this parameter.
\end{abstract}

Keywords: Karst aquifer. Underground water flow. Salinity.

Resumo: O trabalho apresenta a caracterização hidrogeológica de uma área rural de aproximadamente $130 \mathrm{~km}^{2}$, localizada entre os municípios de Assú/RN e Carnaubais/RN, visando obter informações para melhorar a utilização das suas águas subterrâneas em demandas hídricas pontuais. Os procedimentos consistiram no cadastramento de poços no trecho selecionado e na execução de uma sondagem exploratória realizada com equipamento de perfuração a percussão. Nessas etapas foram obtidos dados estratigráficos, bem como de medição do nível da água dos poços e de condutividade elétrica das águas. Na referida área foi caracterizada a ocorrência de depósitos aluvionares antigos de idade quaternária, sobrepostos a rochas carbonáticas da Formação Jandaíra de idade cretácea. Alguns setores são desprovidos das coberturas aluvionares e, portanto, afloram os calcários da Formação Jandaíra. Tais depósitos aluvionares antigos constituem o que foi denominado nesse trabalho de Aquífero Aluvial I, ao passo que Formação Jandaíra equivale ao aquífero homônimo. O Aquífero Aluvial I, com espessura máxima de 64,0 metros, na área de estudo, desenvolve espessura saturada em trechos restritos da área, num dos quais revelou pontualmente uma interconexão hidráulica com o Aquífero Jandaíra. De fato, o Aquífero Aluvial I funciona predominantemente como uma unidade de recepção e transferência/recarga de água de chuva para o Aquífero Jandaíra subjacente. O Aquífero Jandaíra é de natureza cárstico-fissural, sendo composto predominantemente por calcários puros a arenosos, com intercalações de argilitos e margas. Os poços avaliados interceptando o referido aquífero atingiram a profundidade máxima de 122,0 metros. O fluxo das águas subterrâneas nesse aquífero coincide com a declividade geral do terreno, de oeste para leste (no sentido do vale do Rio Açu). A superfície potenciométrica é bem definida e está provavelmente associada à ocorrência de condutos cársticos estreitamente interligados. As águas do Aquífero Jandaíra no setor estudado são doces a ligeiramente salobras. Aproximadamente $71 \%$ das águas avaliadas apresentaram sólidos totais dissolvidos inferior a $1000 \mathrm{mg} / \mathrm{L}$, portanto abaixo do valor máximo permitido pelos padrões de potabilidade para esse parâmetro.

Palavras-chave: Aquífero cárstico. Fluxo subterrâneo. Salinidade.

\footnotetext{
${ }^{1}$ Universidade Federal do Rio Grande do Norte. Departamento de Geologia (brazdf@ geologia.ufrn.br).

${ }^{2}$ Universidade Federal do Rio Grande do Norte. Departamento de Geologia (paula.stein@gmail.com).

${ }^{3}$ Universidade Federal do Rio Grande do Norte. Departamento de Geologia (germano@geologia.ufrn.br).

${ }^{4}$ Universidade Federal do Rio Grande do Norte. Departamento de Geologia (narendra@ geologia.ufrn.br).
} 


\section{INTRODUÇÃO}

Os aspectos hidrogeológicos caracterizados neste estudo se concentraram numa área rural com aproximadamente $130 \mathrm{~km}^{2}$, situada no setor centro-setentrional do Estado do Rio Grande do Norte, à margem esquerda do baixo curso da $\mathrm{Ba}-$ cia Hidrográfica do Rio Açu. A área estudada está inserida parcialmente nos municípios de Assú/RN e Carnaubais/RN, mais precisamente a cerca de $30 \mathrm{~km}$ ao norte da sede de Assú, e $5 \mathrm{~km}$ ao sul da sede de Carnaubais, tomando como referência a rodovia $\mathrm{RN}-118$, que constitui o principal acesso à área (Figura 1).

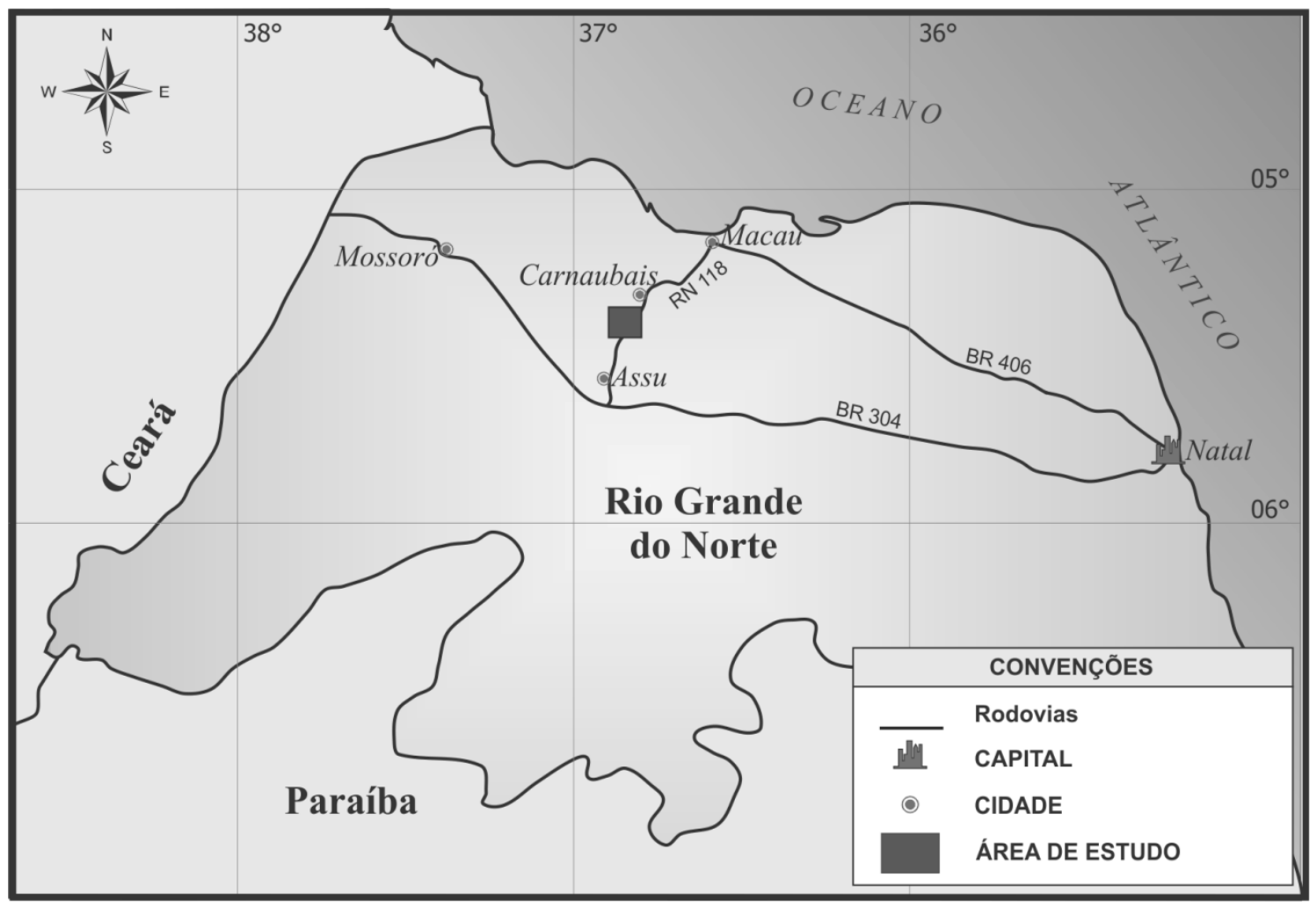

Figura 1 - Localização geográfica da área de estudo, setor centro-setentrional do Estado do Rio Grande do Norte

Figure 1 - Geographic location of the studied area, central- northern sector of Rio Grande do Norte State

Pertencendo ao contexto semiárido do Estado do Rio Grande do Norte, a área está geologicamente posicionada num trecho da Bacia Sedimentar Potiguar emersa, de idade Cretácea. As principais unidades aquíferas regionais dessa bacia são o Aquífero Açu, basal, composto por arenitos da Formação homônima e, sobrejacente, o Aquífero Jandaíra, composto pelas rochas carbonáticas, notadamente calcários com intercalações de margas, da Formação homônima. Ambas as unidades detêm importantes reservas de águas subterrâneas (SERHID, 1998), sendo apenas o Aquífero Jandaíra aflorante na área de estudo.

Estudos regionais indicam que a espessura da Formação Jandaíra pode alcançar 600 metros na porção mais profunda (depocentro) da Bacia Potiguar, embora as espessuras mais importantes, do ponto de vista hidrogeológico, tenham sido caracterizadas entre 50 e 150 metros, e cujo os poços apresentaram vazões variando entre 10 a $50 \mathrm{~m}^{3} / \mathrm{h}$ (Mistreta, 1984).

\section{Objetivos e justificativas}

O levantamento e caracterização dos aspectos hidrogeológicos foi realizado no intuito de ampliar o conhecimento sobre a ocorrência de águas subterrâneas rasas deste setor, permitindo assim integrá-las em futuros planejamentos quanto ao uso mais efetivo dos recursos hídricos subterrâneos locais.

Na região, tem-se como principal atividade econômica a indústria petrolífera, além da agricultura irrigada, em grande escala utilizando águas superficiais principalmente do Rio Açu, que é alimentado e perenizado por águas acumuladas na Barragem Armando Ribeiro Gonçalves, situada 
à montante, e águas subterrâneas de aluviões do mesmo rio. $\mathrm{O}$ abastecimento de água para consumo humano das comunidades rurais se dá através de cacimbões instalados nas planícies fluviais do Rio Açu (aquífero aluvial Quaternário) e/ou através de carros pipas. Para outros usos diversos (atividades agrícolas pontuais, usos domésticos menos nobres, animais, etc.), em muitos casos, são utilizados poços captando águas da porção mais rasa do Aquífero Jandaíra. Localmente, não se tem registro de captação de águas do Aquífero Açu.

Desta forma, este estudo pretende caracterizar a ocorrência de águas subterrâneas na área, visando indicar a melhor opção para explotação dessas águas no intuito de atender a pequenas e pontuais demandas hídricas tanto para usos menos nobres, de uma forma geral, e em particular para obtenção de águas para consumo humano pela população rural dispersa.

\section{Procedimentos metodológicos}

De posse do mapa geológico da área (Bezerra et al., 2009), procedeu-se ao reconhecimento das unidades em campo, no qual foram registrados alguns afloramentos de rochas carbonáticas da Formação Jandaíra e de materiais sedimentares de depósitos aluviais quaternários.

Em seguida, foi efetuado o inventário (cadastramento) de poços existentes no trecho selecionado, acompanhado da medição do nível estático através de medidor elétrico de nível de água, e da obtenção dos valores da condutividade elétrica da água. Este último parâmetro foi determinado fazendo uso do mesmo equipamento de medição do nível estático, o qual possui sensor de condutividade elétrica acoplado. Para avaliação, os resultados de condutividade elétrica foram transformados em valores de sólidos totais dissolvidos (STD), utilizando um fator de conversão conforme Hem (1985).

Com os resultados do cadastro, num ponto especifico da área foi possível proceder à locação e execução de uma sondagem exploratória de reconhecimento (denominada PS-ET), com equipamento de perfuração à percussão, para complementar a avaliação e interpretação das unidades hidroestratigráficas de sub-superfície. As amostras da perfuração foram descritas a cada metro perfurado e obtidos dados de nível da água.

No total foram selecionados 08 (oito) pontos de interesse ao estudo, dos quais 07 (sete) constituem poços obtidos do cadastramento e 01 (um) trata da sondagem (PS-ET) realizada. Tods os poços contam com os respectivos perfis litológico-construtivos.
As cotas topográficas do terreno dos pontos de interesse foram obtidas a partir de imagens SRTM (Shuttle Radar Topography Mission), disponibilizadas gratuitamente no site da Empresa Brasileira de Pesquisa Agropecuária (EMBRAPA, 2005), e trabalhadas no ambiente do software ArcGIS 10.

A avaliação dos perfis litológicos e construtivos resultou na elaboração de seções hidrogeológicas confeccionadas com auxilio do software CorelDRAW X5. As referidas seções permitiram a caracterização de subsuperfície, notadamente quanto à disposição dos sistemas aquíferos, conexão hidráulica e avaliação do componente estrutural. A configuração da superfície potenciométrica do Aquífero Jandaíra na área de estudo foi determinada por interpolação de valores de carga hidráulica pelo método de krigagem através do sofware Surfer 9.

Estas atividades permitiram a caracterização hidrogeológica do trecho selecionado, especificamente no que diz respeito ao modelo hidrogeológico conceitual, indicação da unidade aquífera rasa mais promissora, interpretação potenciométrica da área e avaliação da salinidade das águas subterrâneas.

\section{CARACTERIZAÇÃo DA ÁREA}

\section{Geologia e aspectos hidrogeológicos}

A Bacia Sedimentar Potiguar, localizada no extremo nordeste do Brasil, insere-se em grande parte no Estado do Rio Grande do Norte, e apenas sua borda oeste no Estado do Ceará, possuindo uma área de $60.000 \mathrm{~km}^{2}$, da qual, 24.000 $\mathrm{km}^{2}$ estão emersos (Bertani et al. 1990). Na Figura 2 é destacado o setor estudado no âmbito da referida bacia, cujas rochas carbonáticas cretáceas da Formação Jandaíra constituem o arcabouço/substrato litológico principal no âmbito considerado.

De acordo com Bezerra et al., (2009) se verifica que na área de estudo aflora a sequência litoestratigráfica a seguir elencada, a qual pode ser visualizada no mapa geológico da Figura 3.

(i) Depósitos aluvionares de canal (Quaternário): areias quartzosas médias a grossas, com estratificação cruzada.

(ii) Depósitos aluvionares de planície de inundação (Quaternário): siltes, argilas e subordinadamente areias finas, laminados de coloração escura, ricos em matéria orgânica, bioturbados.

(iii) Depósitos aluvionares antigos (Quaternário): areias, cascalhos e argilas, pouco litificadas e/ou inconsolidadas. 
(iv) Formação Jandaíra (Cretáceo): rochas carbonáticas (predominando calcários), classifica- dos como calcarenitos e calcilutitos bioclásticos, cinza claros e amarelados e margas.

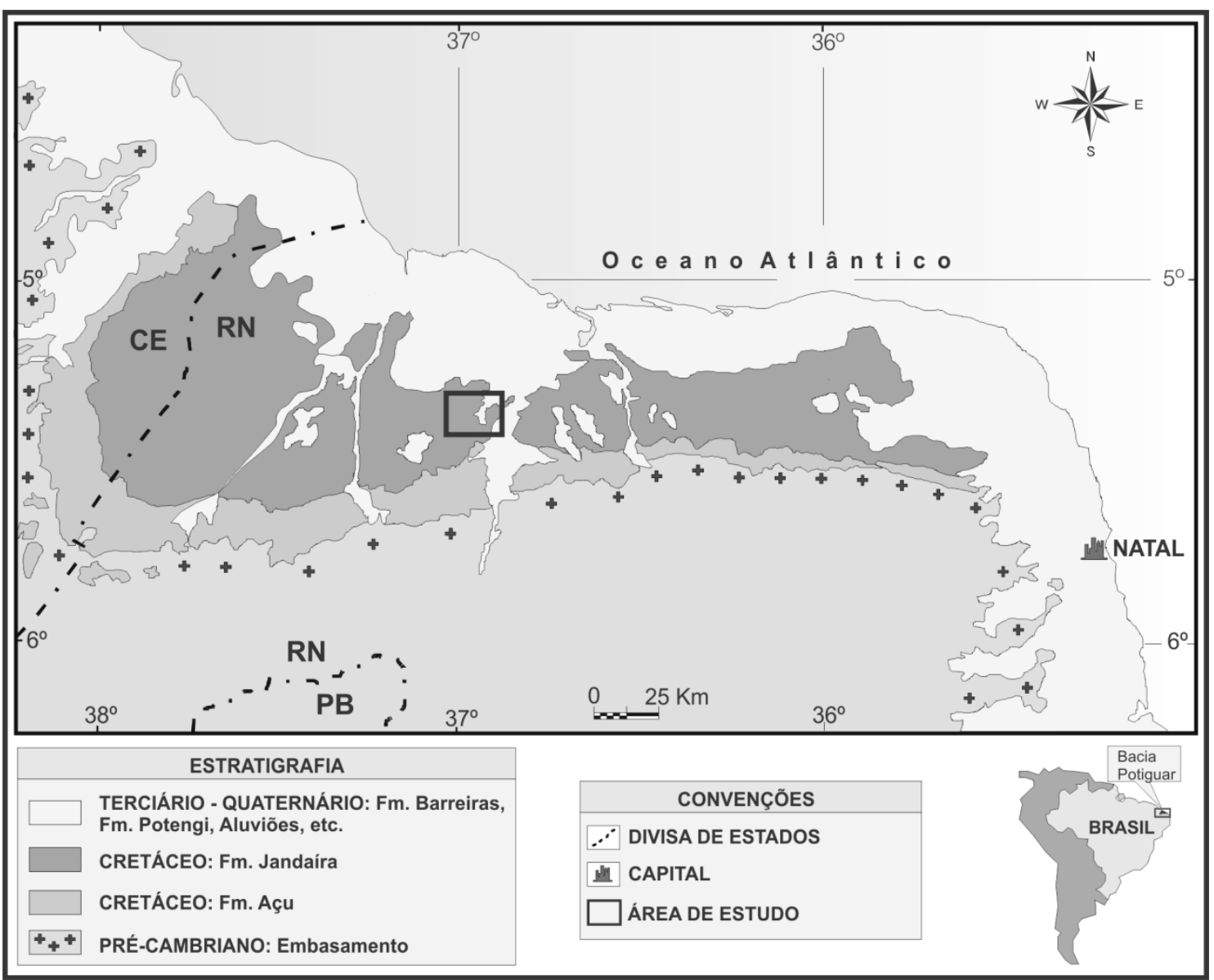

Figura 2 - Bacia Sedimentar Potiguar e suas principais unidades litoestratigráficas regionais aflorantes na parte emersa (modificado de Dantas, 1998)

Figure 2 - Potiguar Sedimentary Basin and its main lithostratigraphic outcropping units in the exposed domain of the basin (modified from Dantas, 1998)
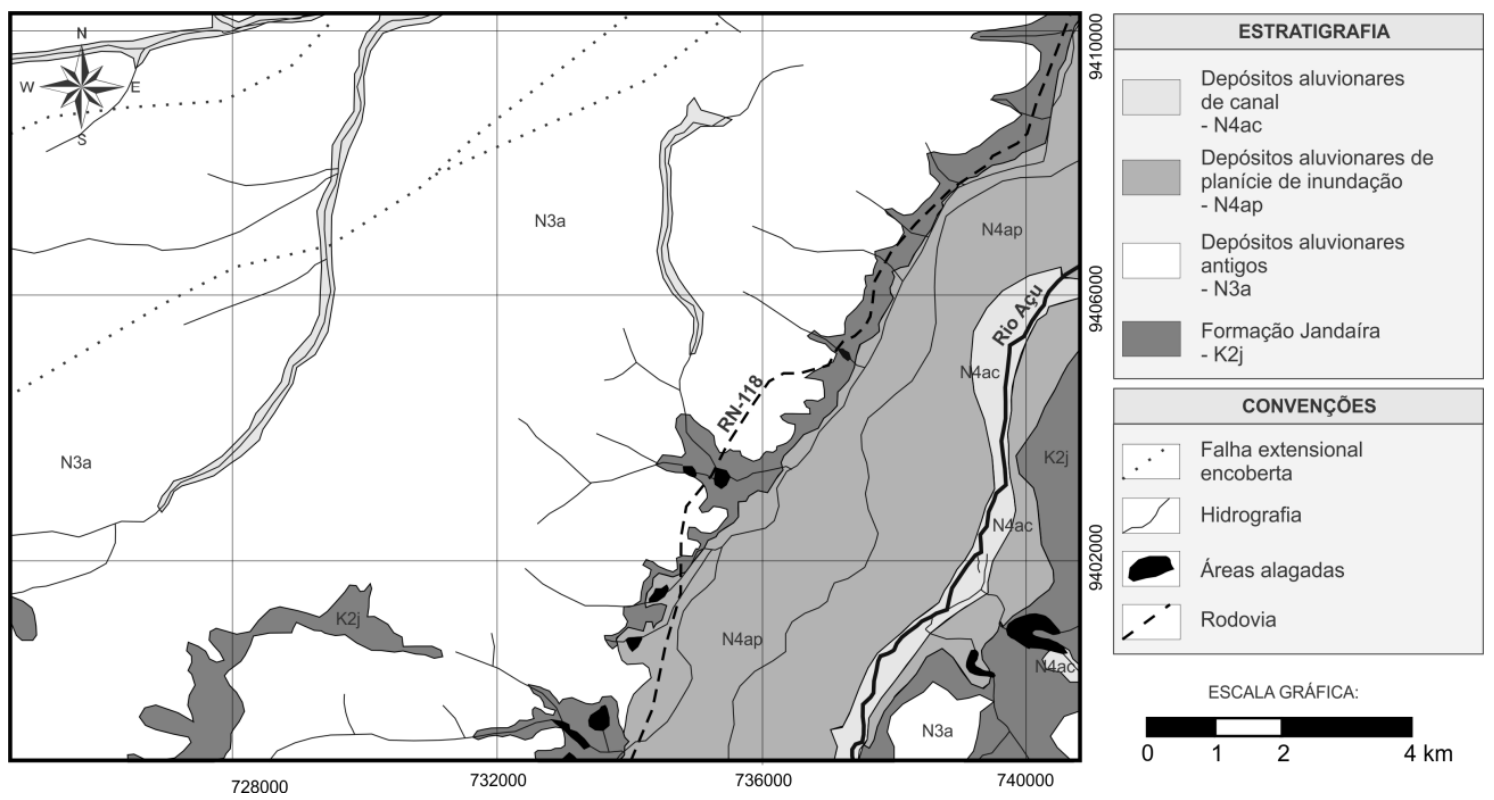

Figura 3 - Unidades geológicas aflorantes na área de estudo (Bezerra et al., 2009)

Figure 3 - Outcropping geological units in the studied area (Bezerra et al., 2009) 
O embasamento cristalino Pré-cambriano, embora não seja aflorante na área, constitui o arcabouço regional e local das unidades cretáceas da Bacia Potiguar, sendo composto por rochas ígneas e metamórficas (granitos, granodioritos, gnaisses, xistos, mármores, ortognaisses, etc.). Em termos de ocorrência espacial, na área de estudo predomina aflorando os depósitos aluvionares quaternários antigos, que aparecem formando os domínios topograficamente mais elevados e respectivas vertentes da margem esquerda do vale do Rio Açu, sendo evidente sua sobreposição estratigráfica aos calcários da Formação Jandaíra.

Os depósitos aluvionares de canal e os depósitos aluvionares de planície de inundação, que constituem os depósitos aluvionares mais recentes, correspondem aos sedimentos ligados ao canal ativo do referido rio, e também repousam sobre os calcários da Formação Jandaíra, afloran- do no setor leste, aproximadamente.

Afloramentos da Formação Jandaíra ocorrem principalmente ao longo de uma faixa NE$\mathrm{SW}$, coincidente com o acesso principal da área (RN-118), e no extremo leste alternando com faixas de ocorrência dos depósitos aluvionares. $\mathrm{Na}$ maior parte da área não se registra em superfície a ocorrência de cavernas e sumidouros, talvez por estarem encobertos pelos depósitos aluviais citados. Nos trechos de calcários aflorantes, observam-se algumas feições cársticas de absorção (sumidouros), porém de maneira dispersa.

A Formação Jandaíra aflorante pode ser exemplificada como ilustrado na Figura 4. Percebe-se a alternância de calcários puros intercalados com calcários argilosos ou margas, cujos contatos definem planos de estratificação ao longo dos quais também são desenvolvidos os carstes.

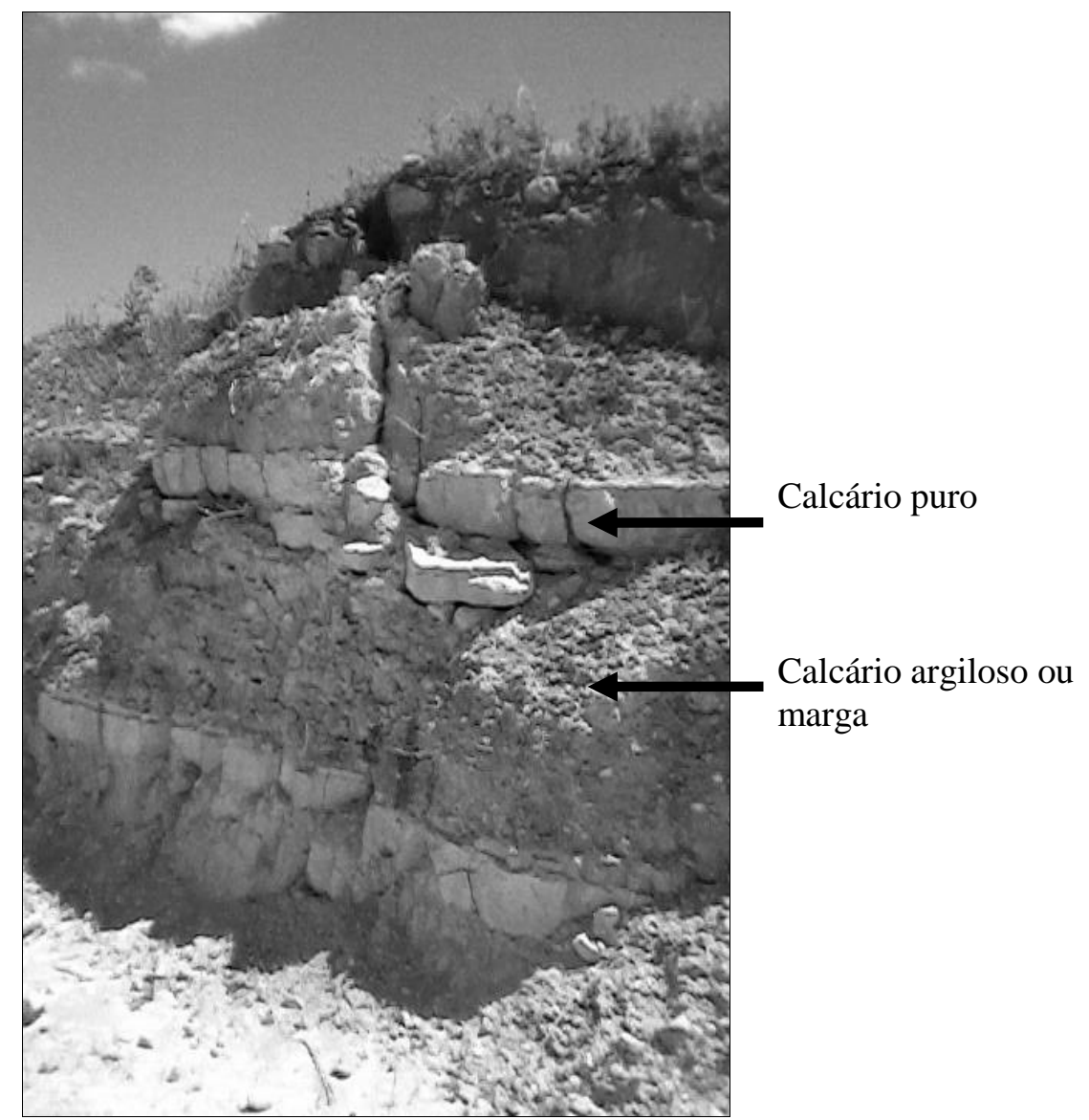

Figura 4 - Níveis de calcário alternando com níveis de margas formando planos de estratificação na Formação Jandaíra, às margens da rodovia RN-118

Figure 4 - Limestone and interspersed marls of the Jandaira Formation along the RN-118 highway

Em sistemas aquíferos cársticos, principalmente nos sistemas aquíferos formados por rochas carbonáticas solúveis, o processo de carstificação, como ilustrado teoricamente na Figura 5, é associado à infiltração e percolação de águas de chuva simultaneamente à dissolução do arcabouço rochoso carbonático ao longo de planos de fratura e de outras descontinuidades (como os planos de acamamento, na Figura 4, na área estudada).

Portanto, as águas infiltradas circulam pelas fraturas do maciço rochoso e ao mesmo tempo reagem quimicamente dissolvendo a rocha carbo- 
nática. Prosseguindo o processo, os constituintes químicos dissolvidos da rocha são transportados ionicamente sob um gradiente hidráulico que induz o fluxo das águas subterrâneas para as áreas de descarga (Goldscheider e Drew, 2007), favorecido pela declividade regional/gradiente da própria bacia sedimentar. Com isto, ocorre progressi- vamente o rebaixamento do nível potenciométrico em função do aprofundamento e alargamento simultâneos dos condutos ao longo de fendas, fraturas e planos de acamamento sedimentar, aumentando assim a erosão química vertical e a permeabilidade secundária (Mandel e Shiftan, 1981).

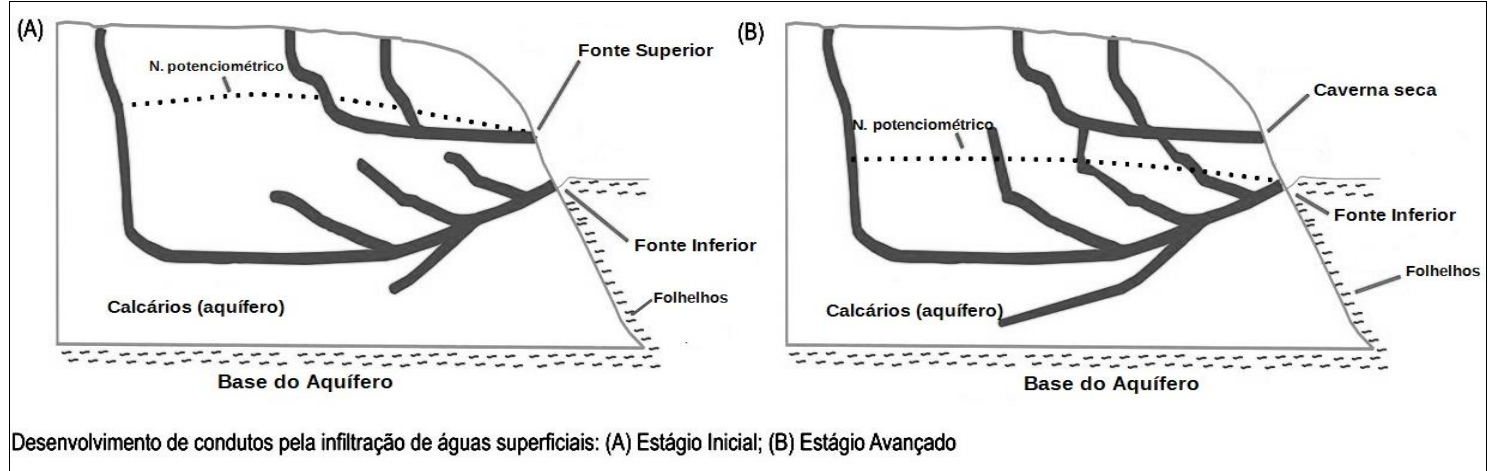

Figura 5 - Conceitos sobre o desenvolvimento de estruturas cársticas, mostrando o rebaixamento do nível das águas subterrâneas no decorrer do tempo em função do maior desenvolvimento das cavidades cársticas (modificado de Mandel e Shiftan, 1981)

Figure 5 - Concepts about the development of karstic structures, showing the lowering of groundwater level along time as function of larger development ok karstic cavities (modified from Mandel and Shiftan, 1981)

Inicialmente, como hipótese, a dissolução e o desenvolvimento da porosidade cársticofissural da Formação Jandaíra se deu no período de exposição sub-aérea da referida formação, no Turoniano/Campaniano (entre 93 e 70 milhões de anos) (Neto, 2006). Posteriormente, a carstificação pode ter se desenvolvido em profundidade, após os calcários da Formação Jandaíra terem sido soterrados pelos depósitos aluvionares quaternários mais antigos, no contexto local.

Convém ressaltar, que no extremo noroeste da área, dados estruturais regionais demonstrados no mapa geológico de Bezerra et al., (2009), apresentado na Figura 3, registram a ocorrência de falhas extensionais do embasamento cristalino, por meio das quais se desenvolveu parte do arcabouço estrutural da bacia sedimentar no âmbito regional, sendo caracterizadas como pertencentes ao sistema de Falhas de Carnaubais. A reativação, no Cenozóico, deste sistema de falhas e de outras falhas a ele subordinadas (Moura-Lima et al., 2010; Moura-Lima et al., 2011; Maia et al., 2012), pode também ter contribuído na criação de zonas fraturadas/falhadas ao longo das quais se ampliou a carstificação das rochas carbonáticas cretáceas da Formação Jandaíra tanto no âmbito regional, quanto na área estudada.

\section{Pluviometria}

Segundo dados obtidos da Estação Agrometeorológica da Base Física do Município de
Ipanguaçu, para a série de 1993 a 2007, a precipitação total anual é da ordem de $639,5 \mathrm{~mm}$. As médias mensais variam desde $3,8 \mathrm{~mm}$ (em outubro) a 160,2 $\mathrm{mm}$ (em março). O período chuvoso se estende de janeiro a julho, com pico no mês de março (Figura 6), quando provavelmente ocorre recarga dos aquíferos.

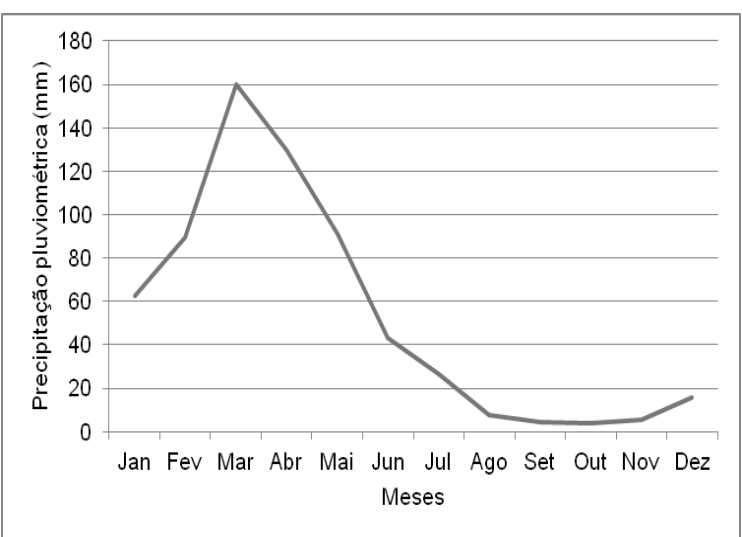

Figura 6 - Evolução da precipitação pluviométrica (mm) média mensal (1993 a 2007) obtida da Estação Agrometeorológica localizada no município de Ipanguaçu, representativa da área de estudo

Figure 6 - Evolution of monthly mean pluviometric precipitation (mm; 1993 to 2007), based on data from the Agrometerological Station located in the Ipanguaçu county, representative of the studied area 


\section{RESULTADOS}

\section{Hidrogeologia da Área}

\section{Sondagem exploratória de reconhecimento}

A execução da sondagem (denominada PS-ET) foi realizada pelo método de perfuração à percussão, e visou o reconhecimento das características estratigráficas, litológicas e hidrogeológicas da área estudada.

A seguir são descritos aspectos operacionais, litológicos e hidráulicos obtidos da sondagem, que atingiu 96,0 metros de profundidade:

- Na porção superior da sondagem, entre a superfície do terreno e o topo dos calcários da Formação Jandaíra, a perfuração foi executada usando trépano de 10 polegadas. Nesse intervalo foi verificada a ocorrência dos depósitos aluvionares antigos, denominados neste trabalho de Aquífero Aluvial I, tendo sido registrado no furo até a profundidade de 42,0 metros. Compõem-se predominantemente por areias grossas a cascalhos quartzosos, contendo também feldspatos e com alguns níveis argilosos intercalados, pouco compactos. O nível estático representativo deste aquífero foi da ordem de 38,0 metros, indicando que o Aquífero Aluvial I apresentou localmente uma espessura saturada de 4,0 metros.

- Antes de prosseguir a perfuração a partir do topo dos calcários, procedeu-se ao isolamento da porção litológica superior do furo, que corresponde aos depósitos aluvionares, mediante a instalação de um revestimento provisório de ferro galvanizado desde a superfície até topo dos calcários (tendo a base do revestimento ultrapassado em cerca de 1,0 metro o topo do referido pacote carbonático), totalizando, portanto, 43,0 metros de revestimento provisório. Foi feita também a colocação de um selo de bentonita pelotizada no espaço anelar entre o revestimento provisório e a formação geológica dos depósitos aluvionares. $\mathrm{O}$ isolamento hidráulico foi garantido, na medida em que o interior do revestimento se apresentou completamente seco (devido à retenção de água subterrânea dos depósitos aluvionares sobrejacentes), e então se retomou a perfuração com diâmetro menor, com trépano de 8 polegadas, na parte interna do revestimento de 10 polegadas. Este procedimento garantiu que as entradas de água e o cor respondente nível estático fossem representativos dos condutos/fraturas nos calcários do Aquífero Jandaíra. As rochas carbonáticas interceptadas compreenderam calcários cinza puros a arenosos e margosos, intercalados com argilitos de coloração escura. Em geral os intervalos entre 42,0 e 62,0 metros e entre 80,0 e 96,0 metros mostraram calcários intercalados com margas e argilitos, e o intervalo entre 62,0 e 80,0 metros revelou preferencialmente calcários arenosos e fossilíferos. O registro das primeiras entradas de água (fraturas e/ou condutos cársticos) ocorreu a partir dos 52,0 metros de profundidade. Com o término da perfuração o nível da água ascendeu para a posição de 38,0 metros, isto é, ligeiramente acima do topo das rochas carbonáticas, evidenciando uma drenança vertical ascendente.

$\mathrm{Na}$ referida sondagem (PS-ET) não se procedeu a sua completação definitiva, tendo os dados sido obtidos no próprio furo, o qual, ao término das operações foi totalmente selado e fechado, para evitar possíveis efeitos de contaminação.

Apesar de ter sido localmente registrada a drenança vertical ascendente no Aquífero Jandaí$\mathrm{ra}$, admite-se neste estudo que o aquífero seja de natureza livre. Em geral, um aquífero confinado/semi-confinado pode ser caracterizado por 3 condições básicas (Feitosa et al., 2008):

- A camada aquífera deve estar situada entre duas formações geológicas impermeáveis/semi-impermeáveis;

- O nível potenciométrico do aquífero confinado/semiconfinado deve estar posicionado acima do topo do aquífero, indicando drenança vertical ascendente;

- A camada aquífera deve permanecer saturada quando do bombeamento e explotação por poços.

Quanto à primeira condição, verificou-se que o Aquífero Aluvial I, sobrejacente ao Aquífero Jandaíra, não mostra caráter litológico que permita classificá-lo como aquiclude ou aquitardo.

Quanto à segunda condição, a drenança vertical ascendente observada no furo corresponde a uma informação pontual, não sendo possível 
afirmar efetivamente que todo o pacote carbonático esteja sob pressão de camada confinante/semiconfinante a ele sobrejacente, e considerando também que a camada sobrejacente não tem caráter de aquiclude ou aquitardo. Contudo, no contexto local da sondagem PS-ET, se observa a presença de uma intercalação de marga/argilito na porção superior do pacote carbonático (Figuras 8 e 9), a qual deve estar agindo como camada confinante do conduto interceptado pela sondagem (a partir de 52,0 metros).

Quanto à terceira condição, não se tem informações necessárias para afirmar que todo o pacote carbonático esteja saturado, pois até mesmo durante a perfuração da sondagem, a partir do topo do Aquífero Jandaíra, percebia-se que, antes de interceptar condutos/fraturas com água, eram ultrapassados intervalos de condutos e fraturas secas, os quais teoricamente deveriam estar sob o domínio da zona saturada. Além disto, não se tem dados de bombeamento para averiguar até que nível seria alcançado o rebaixamento (ou nível dinâmico) em relação às entradas de água do maciço carbonático, de modo a se confirmar se essas permaneceriam saturadas ou seriam esvaziadas durante o bombeamento.

Estudos efetuados nas porções mais rasas do Aquífero Jandaíra em outros setores da bacia (Diniz Filho et al., 2008; Stein, 2013), revelaram também mecanismos de ascensão do nível da água nos poços, e, naqueles casos, foi também considerado como livre.
Portanto, o Aquífero Jandaíra estudado é considerado como sendo do tipo livre, haja vista que os depósitos aluvionares antigos a ele sobrejacentes não tem caráter de aquiclude ou aquitardo, e tampouco demonstra uma pressão confinante acima do Aquífero Jandaíra que viesse a ser superior à pressão atmosférica, em toda a sua extensão de ocorrência espacial.

No mesmo furo de sondagem, a elevação do nível da água dos condutos da zona saturada do Aquífero Jandaíra foi estabilizado numa posição equivalente à posição do nível da água do Aquífero Aluvial I sobrejacente, também de caráter livre. A estabilização dos níveis de ambos os aquíferos a uma altura equivalente pode demonstrar uma interconexão hidráulica entre ambas as unidades aquíferas que, pontualmente, estariam representando um sistema aquífero hidráulico único, de natureza livre. Para auxiliar na confirmação do caráter livre do aquífero, seria necessário executar testes de aquífero para avaliar a evolução dos rebaixamentos e interferências entre as cargas hidráulicas, através de poços multiníveis, o que não pôde ser realizado neste estudo.

\section{Inventário de pontos de água}

$\mathrm{O}$ presente estudo abrangeu as informações obtidas em 08 (oito) pontos de água, cuja localização é mostrada na Figura 7. Os parâmetros construtivos e hidráulicos são apresentados na Tabela 1.
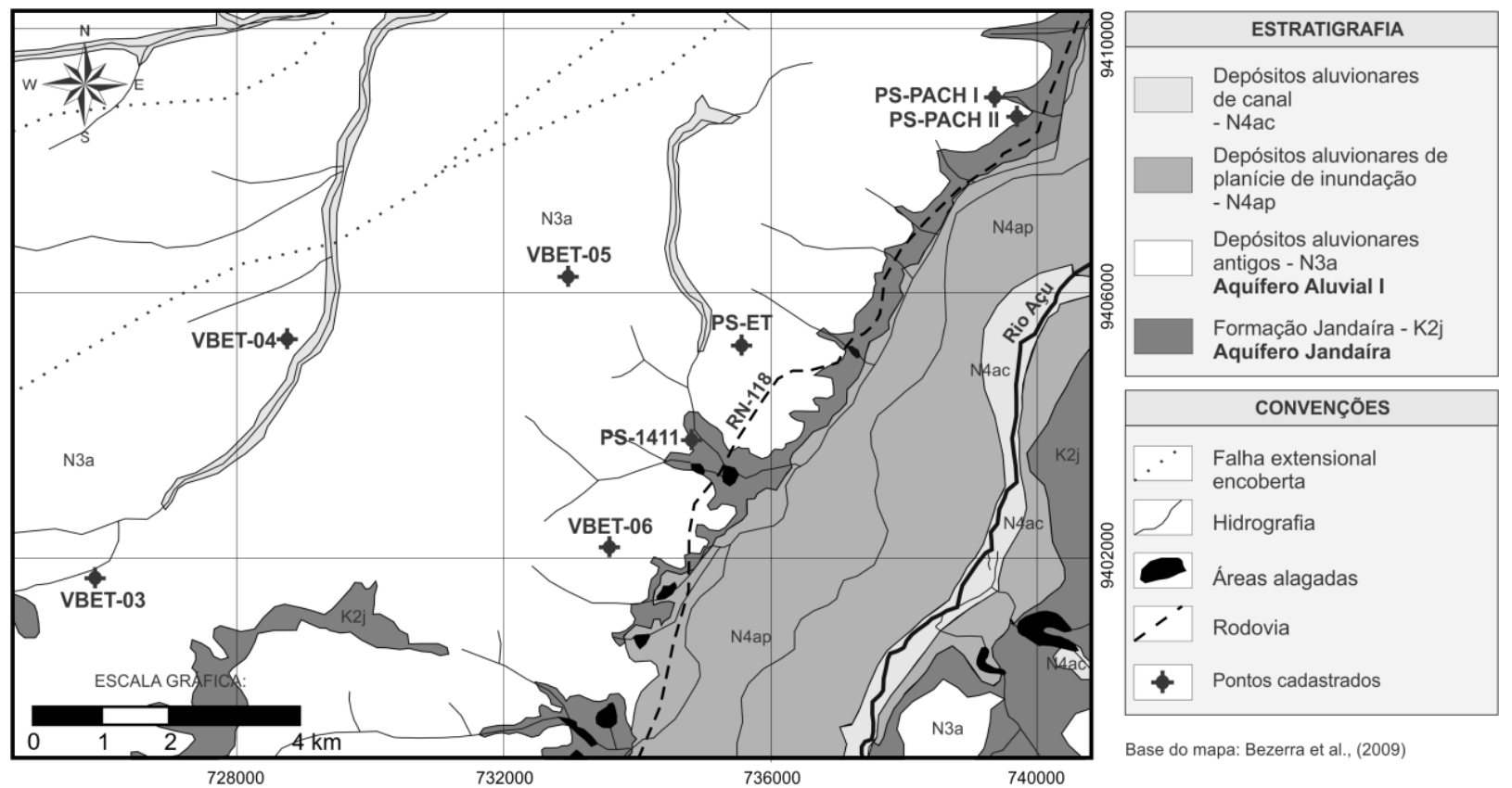

Figura 7 - Localização dos pontos de águas subterrâneas e o contexto geológico da área

Figure 7 - Location of groundwater points and geological context of the area 
Tabela 1 - Dados construtivos e hidráulicos dos poços e sondagem exploratória

Table 1 - Constructive and hydraulic data from wells and exploratory drilling

\begin{tabular}{|c|c|c|c|c|c|c|c|c|}
\hline \multirow[t]{2}{*}{ Ponto } & \multirow{2}{*}{$\begin{array}{l}\text { Prof. } \\
\text { (m) }\end{array}$} & \multirow{2}{*}{$\begin{array}{l}\text { Diâmetro de } \\
\text { revestimento } \\
\text { (polegadas) }\end{array}$} & \multirow{2}{*}{$\begin{array}{l}\text { Intervalo da } \\
\text { seção filtrante } \\
\text { (m) }\end{array}$} & \multicolumn{2}{|c|}{$\begin{array}{l}\text { Espessura lito- } \\
\text { lógica }(\mathrm{m})\end{array}$} & \multicolumn{2}{|c|}{$\mathrm{NE}(\mathrm{m})$ *2 } & \multirow{2}{*}{$\begin{array}{l}\text { Espessura } \\
\text { saturada (m) } \\
\text { do AqA }\end{array}$} \\
\hline & & & & $\mathrm{AqA}$ & AqJ & $\mathrm{AqA}$ & $\mathrm{AqJ}$ & \\
\hline VBET-06 & 65 & $4 "$ & $52-56$ & 19 & 46 & 0 & \multirow{2}{*}{$\underset{* 3}{5,3}$} & 0 \\
\hline VBET-05 & 65 & $4 "$ & $52-58$ & 64 & 1 & 44,7 & & 19,3 \\
\hline VBET-04 & 62 & $4 "$ & $51-59$ & 0 & 62 & 0 & 18,9 & 0 \\
\hline VBET-03 & 40 & $4 "$ & $35-39$ & 3 & 37 & 0 & 19,8 & 0 \\
\hline PS-PACH I & 122 & $4 "$ & $\begin{array}{l}54-82 \\
98-118\end{array}$ & 0 & 122 & 0 & 26,9 & 0 \\
\hline $\begin{array}{l}\text { PS-PACH } \\
\text { II }\end{array}$ & 112 & $4 "$ & $70-118$ & 0 & 112 & 0 & 16,3 & 0 \\
\hline PS-1411 & 97 & 6“ & $70-90$ & 0 & 97 & 0 & 9,8 & 0 \\
\hline PS-ET & 98 & 10" e 8“ & $\star 4$ & 42 & 56 & 38,0 & 38,0 & 4,0 \\
\hline
\end{tabular}

Prof.=Profundidade; NE=Nível Estático; AqA: Aquífero Aluvial I; AqJ: Aquífero Jandaíra.

*1 No caso da sondagem PS-ET trata do diâmetro de perfuração.

*2 Medições realizadas entre agosto de 2012 e janeiro de 2013, portanto representativas do período seco da região, conforme Figura 6.

*3 Poço não interceptou o Aquífero Jandaíra.

*3 Não foi instalado filtro.

Os poços denominados de PS-PACH I, PS-PACH II e PS-1411 são poços particulares, os quais durante a etapa de cadastramento não se encontravam instalados. Os poços VBET-06, VBET-05, VBET-04 e VBET-03 constituem unidades de monitoramento das águas subterrâneas existentes na área estudada. O ponto PS-ET refere-se à sondagem de reconhecimento realizada no âmbito dessa pesquisa, conforme detalhado no item anterior.

Os referidos pontos estão na maior parte situados espacialmente no domínio aflorante dos depósitos aluvionares antigos, e também na Formação Jandaíra. Dos poços cadastrados, apenas o poço VBET-05 capta águas dos depósitos aluvionares antigos (Aquífero Aluvial I). Os demais poços captam águas nos intervalos dos calcários Jandaíra.

\section{Estrutura hidrogeológica}

$\mathrm{Na}$ maior parte da área estudada foi caracterizada em sub-superfície a ocorrência do Aquífero Aluvial I (correlato aos depósitos aluvionares antigos) repousando sobre o Aquífero Jandaíra (inserido na formação homônima), como evidenciado nos perfis litológicos mostrados na Figura 8 e nas seções hidrogeológicas da Figura 9.
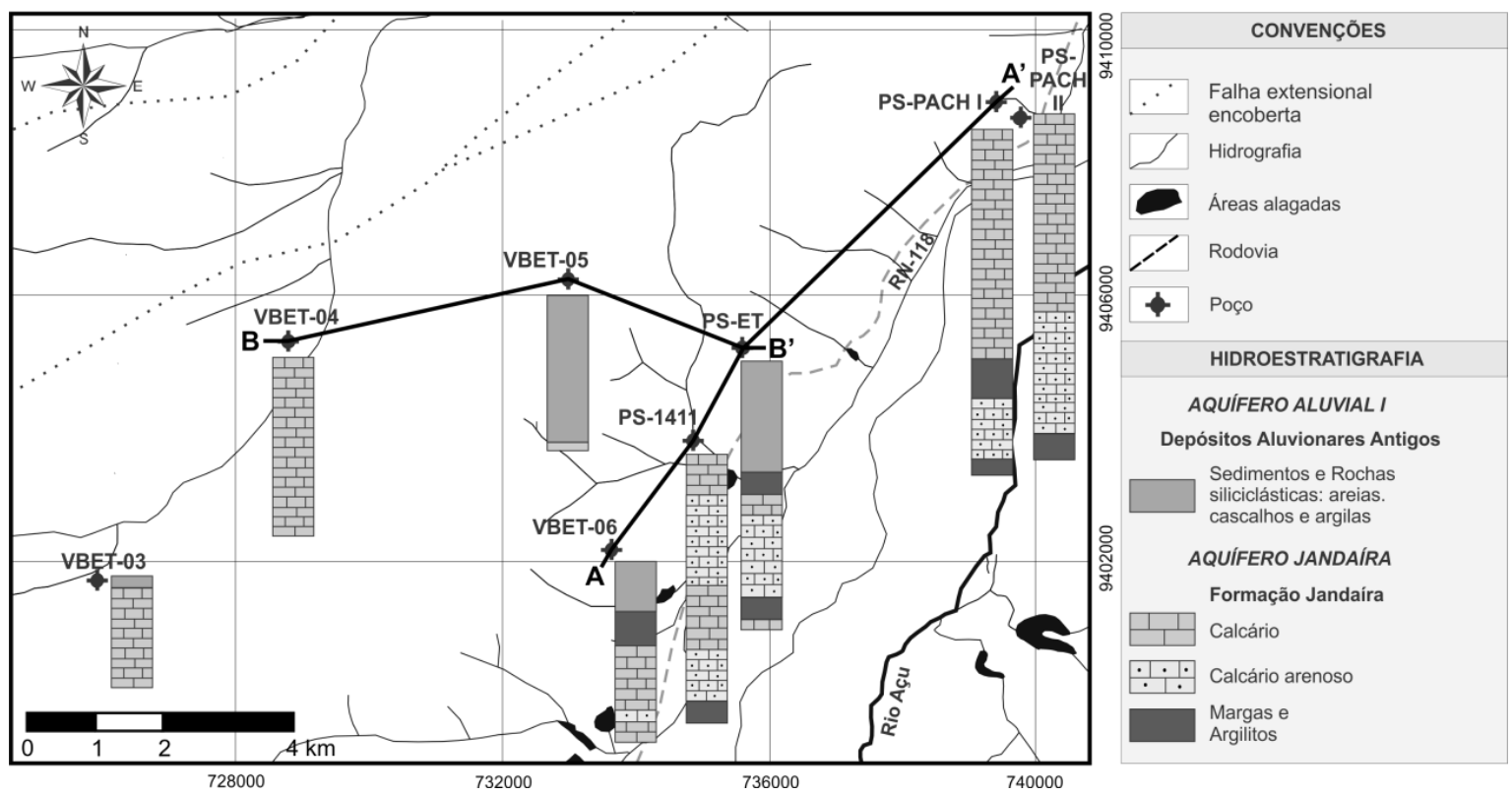

Figura 8 - Perfis litológicos dos poços cadastrados e da sondagem de reconhecimento, com a localização das seções hidrogeológicas (A-A' e B-B') apresentadas na Figura 9

Figure 8 - Lithologic profiles of recorded points with location of hydrogeologic sections (A-A 'and B-B') shown in Figure 9 


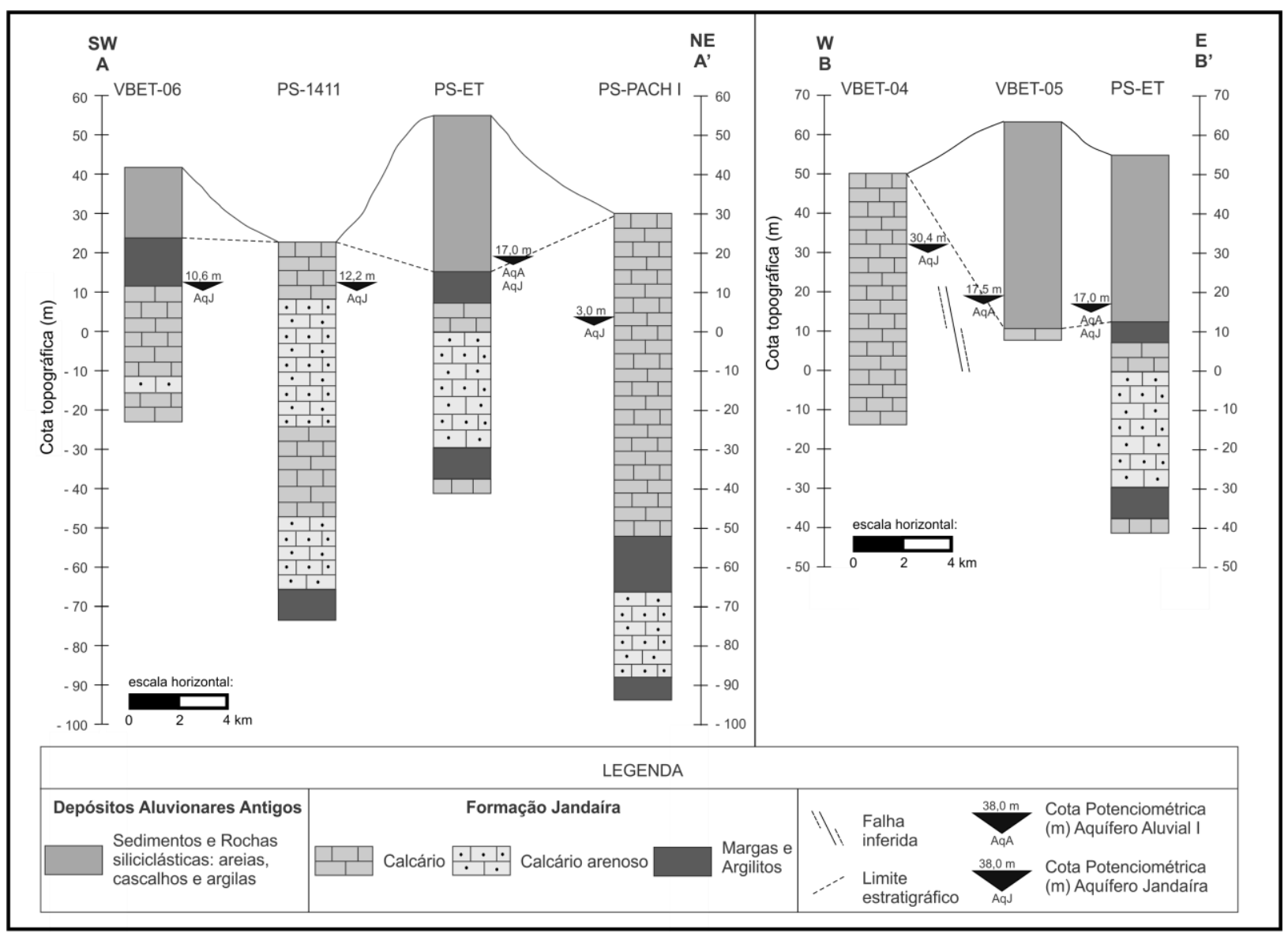

Figura 9 - Seções hidrogeológicas A-A' e B-B' na área de estudo

Figure 9 - Hydrogeological sections A-A' e B-B', in the studied area

Verifica-se a ocorrência do Aquífero Aluvial I com maiores espessuras litológicas na porção central da área (VBET-05, VBET-06 e PSET) (Figura 8). O poço VBET-05 mostrou o maior valor de espessura saturada para essa unidade aquífera, localmente da ordem de 19,0 metros (Tabela 1). Durante a sondagem PS-ET também foi registrada espessura saturada, porém menor, da ordem de 4,0 metros (Tabela 1). Nos demais poços a referida unidade não ocorre ou apresenta-se insaturada. Isso sugere a baixa potencialidade desse aquífero no trecho estudado, que poderá apresentar-se predominantemente seco (insaturado) ou com pequenas espessuras saturadas em locais restritos, notadamente nos períodos chuvosos.

Constata-se que no Aquífero Jandaíra é comum a ocorrência de fácies compostas por calcários puros e calcários arenosos (dominantemente ricos em quartzo) com intercalações de argilitos e margas, notadamente no setor leste da área cadastrada (VBET-06, PS-1411, PS-ET, PS-PACHI e PS-PACHII). Na faixa oeste predominam calcários puros e compactos (VBET-03 e VBET-04).
Seção A-A':

A seção A-A' apresentada na Figura 9, de direção SW-NE, evidencia que o Aquífero Aluvial I desenvolve espessuras litológicas variadas, atestando relatos anteriores. Essas espessuras em alguns trechos são nulas e em outros variam de 19,0 metros (VBET-06) a 42,0 metros (PSET). Verifica-se que nos setores de afloramento dos depósitos aluvionares (nos quais os calcários são mais profundos) a topografia do terreno é elevada quando comparada aos trechos nos quais os calcários são mais rasos. Portanto, estes depósitos aluvionares controlam o relevo da área, configurando as encostas e os vales.

O Aquífero Aluvial I na referida seção desenvolve espessura saturada apenas no PS-ET, e conforme já citado, da ordem de 4,0 metros (Tabela 1). A limitação da espessura saturada pode ser devida às condições climáticas semiáridas locais. De acordo com as indicações das cotas potenciométricas, percebe-se que, nesse ponto da seção, a posição do nível potenciométrico de ambos os aquíferos (Aluvial I e Jandaíra) se ajusta a uma mesma altura potenciométrica, posicionada 
no domínio do Aquífero Aluvial I, podendo demonstrar uma interconexão hidráulica que, pontualmente, estaria representando um sistema aquífero hidraulicamente único e interconectado, corroborando descrições anteriores.

A variabilidade na espessura litológica e limitação da espessura saturada do Aquífero Aluvial I mostradas nesta seção podem revelar sua baixa potencialidade hídrica no trecho avaliado. Desta maneira, há evidências de que o Aquífero Jandaíra seja provavelmente de maior potencial hidrogeológico na área, considerando que deve apresentar maior espessura litológica e maior quantidade entradas de água, o que permite um maior armazenamento e o estabelecimento de uma zona saturada suficiente para proporcionar uma maior produtividade dos poços.

Como pode ser observado pelo posicionamento das cotas potenciométricas do Aquífero Jandaíra na seção, e apesar de ocorrer drenança vertical ascendente, admite-se neste estudo que este aquífero cárstico seja de natureza livre, conforme já citado. Percebe-se que o Aquífero Aluvial I sobrejacente, além de seu caráter litológico permeável, não demonstra condições hidráulicas e de pressão suficientes para impor um confinamento/semi-confinamento ao Aquífero Jandaíra, mesmo que localmente no ponto PS-ET tenha-se registrado o nível potenciométrico ligeiramente acima do seu topo. Entretanto, conforme informado anteriormente, uma camada de marga/argilito situada no topo do Aquífero Jandaíra no local da sondagem PS-ET pode estar proporcionando um confinamento neste ponto.

\section{Seção B-B':}

Na seção B-B' apresentada na Figura 9, de direção W-E, tomando como base o topo do Aquífero Jandaíra (Figura 9), percebe-se em subsuperfície na porção média/oriental da seção (VBET-05 e PS-ET), um posicionamento mais rebaixado do topo dos calcários em relação à porção ocidental, caracterizando provavelmente a ocorrência de uma falha inferida. Diante disto, o setor oriental da seção seria correspondente ao bloco rebaixado da falha (baixo estrutural, ou semi-graben) e o setor ocidental corresponderia ao bloco elevado (alto estrutural, ou horst) (VBET-04).

Convém ressaltar as falhas extensionais localizadas na porção noroeste da área de estudo, as quais são pertencentes ao sistema de falhas de Carnaubais mapeadas por Bezerra et al., (2009), as quais delimitam regionalmente a porção leste do graben central da Bacia Potiguar (Matos, 1987). A provável falha geológica detectada na seção B-B' pode corresponder a um segmento de falha contemporâneo ao referido sistema de falhas Carnaubais, porém não mapeável em termos regionais. Entretanto, este segmento de falha inferida è evidenciado na escala local desta seção, em subsuperfície, tomando como referência o topo do Aquífero Jandaíra. O falhamento pode, também, evidenciar localmente uma das estruturas tectônicas a partir da qual teria se originado e evoluído a carstificação do Aquífero Jandaíra na área.

Percebe-se também na seção, que o Aquífero Aluvial I apresenta espessura litológica máxima de 64,0 metros (Tabela 1) podendo também ter espessura nula, confirmando a ocorrência irregular destes depósitos. As maiores espessuras coincidem com o baixo estrutural do setor oriental, tomando como base o topo do Aquífero Jandaíra.

O Aquífero Aluvial I desenvolve espessura saturada no PS-ET, da ordem de 4,0 metros, e no VBET-05, da ordem de 19,0 metros (Tabela 1), atestando também os relatos anteriores sobre a ocorrência irregular destes depósitos. A limitação da espessura saturada do referido aquífero, pode ser devida às condições climáticas semiáridas locais. Nessas condições, esse aquífero compõe uma unidade de recepção de água no período chuvoso, propiciando a recarga/transferência para o Aquífero Jandaíra subjacente, por drenança vertical descendente, porém não mostra uma efetiva potencialidade para explotação de águas subterrâneas.

\section{Fluxo subterrâneo do Aquífero Jandaíra}

A potenciometria da área evidencia que as águas subterrâneas do Aquífero Jandaíra no domínio estudado escoam no sentido geral de oeste para leste (em direção ao vale do Rio Açu), conforme pode ser visualizado na Figura 10, coincidindo com a declividade geral do terreno. Essa superfície hidrostática bem definida, provavelmente decorre da conexão dos condutos cársticos estreitamente interligados. O comportamento da superfície potenciométrica mostrado nas seções (Figura 9), reflete também a ocorrência do fluxo subterrâneo de oeste para leste.

\section{Salinidade das águas}

A salinidade das águas foi abordada pelo parâmetro condutividade elétrica (CE), a qual foi obtida por meio da sua medição em campo nos poços estudados. Na presente avaliação, optou-se por estimar os valores de sólidos totais dissolvidos (STD) com base na CE obtida em campo. Essa transformação visa a classificação das águas no que tange a salinidade e potabilidade, já que as 
tabelas de referência apontam os sólidos totais dissolvidos como parâmetro principal. Hem (1985) estabelece essa relação mediante um fator que pode variar entre 0,55 e 0,75 em função da concentração dos parâmetros iônicos. Neste trabalho, foi efetuada a multiplicação da CE pelo fator 0,65 para obtenção do valor de STD.

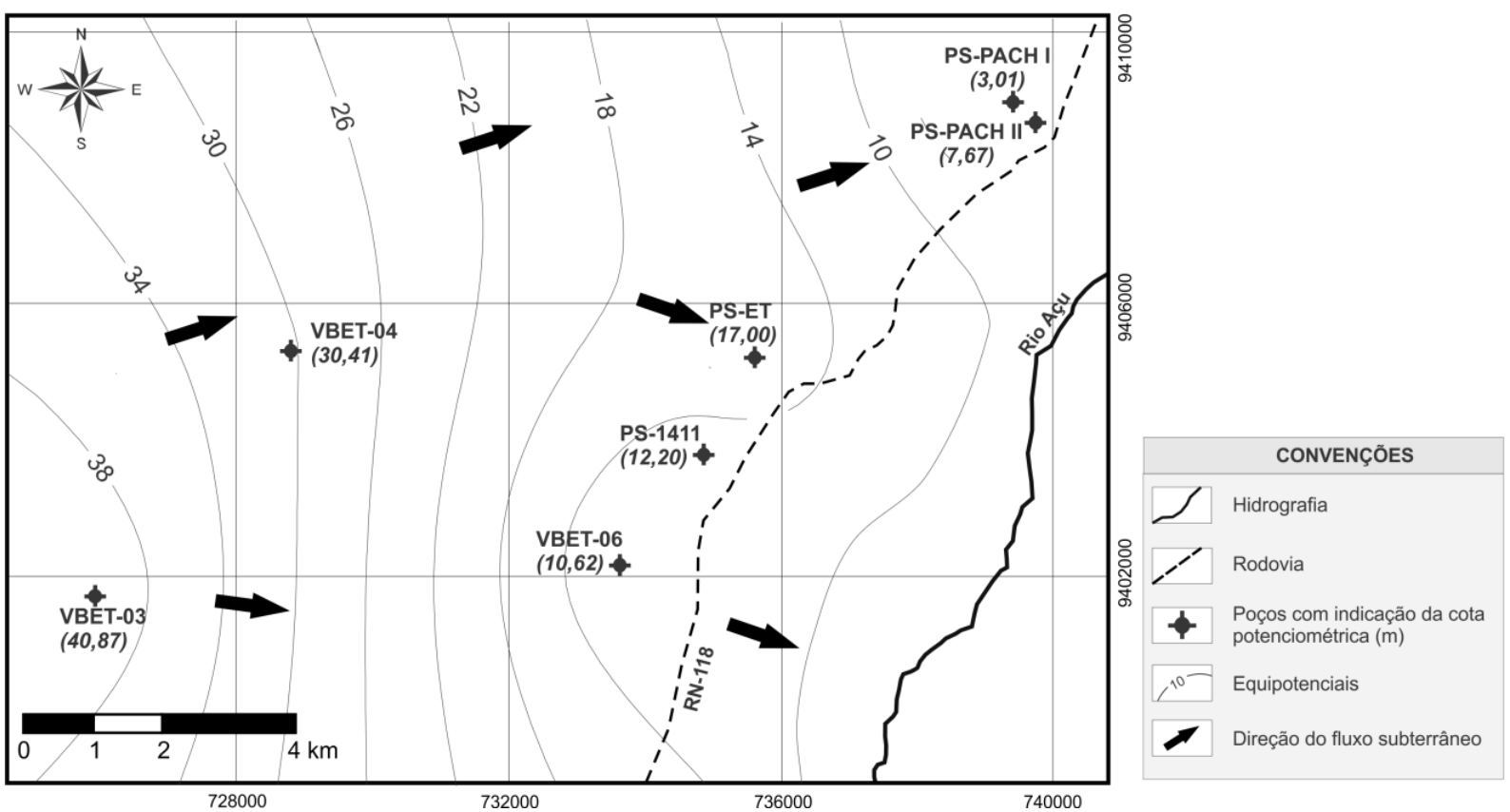

Figura 10 - Mapa potenciométrico do Aquífero Jandaíra

Figure 10 - Potenciometric map of the Jandaira Aquifer

As águas do Aquífero Jandaíra apresentaram STD variando entre 383 e $2007 \mathrm{mg} / \mathrm{L}$, refletindo uma média de $980 \mathrm{mg} / \mathrm{L}$, conforme apresentado na Tabela 2. A distribuição espacial dos resultados se mostrou aleatória, conforme se pode visualizar na Figura 11. Segundo Williams (1985) apud Feitosa et al., (2008), o processo de dissolução das fissuras resulta em condutos diversos, o que torna a permeabilidade do carste variável de um ponto a outro, e em diversas direções no interior do maciço cárstico. De fato, a distribuição da salinidade dessas águas sugere um cenário no qual se podem evidenciar diferentes condições de permeabilidade (ou condutividade hidráulica), influenciando na maior ou menor circulação das águas subterrâneas e, por conseguinte, na menor ou maior concentração salina das águas, respectivamente.

A litologia da unidade aquífera também pode interferir no conteúdo salino dessas águas, o que poderia ser melhor evidenciado a partir de uma amostragem mais ampla e de uma análise mais abrangente das águas.

$\mathrm{Na}$ avaliação da salinidade foram utilizadas as classes de Mcneely et al., (1979), que classifica como doces as águas com até $1000 \mathrm{mg} / \mathrm{L}$ de STD, e como ligeiramente salobras as águas que possuem entre 1001 e $3000 \mathrm{mg} / \mathrm{L}$ de STD. No contexto da análise individual dos resultados (Ta- bela 2) obtidos para o Aquífero Jandaíra, verificase que duas amostras são classificadas como águas ligeiramente salobras (VBET-03 e PS1411) e as cinco restantes (VBET-06, VBET-04, PS-PACH I, PS-PACH II e PS-ET) como águas doces.

Tabela 2 - Condutividade elétrica (CE) das águas subterrâneas obtida em campo e sólidos totais dissolvidos (STD)

Table 2 - Electrical conductivity (EC) of groundwater obtained in the field and total dissolved solids (TDS)

\begin{tabular}{llll}
\hline $\begin{array}{l}\text { Unidade } \\
\text { Aquífera }\end{array}$ & Ponto & $\begin{array}{l}\text { CE } \\
(\mu \mathrm{s} / \mathrm{cm})^{*}\end{array}$ & $\begin{array}{l}\text { STD } \\
(\mathrm{mg} / \mathrm{L})^{*}\end{array}$ \\
\hline \multirow{6}{*}{ AqJ } & VBET-06 & 589 & 383 \\
& VBET-04 & 900 & 585 \\
& VBET-03 & 2192 & 1425 \\
& PS-PACH I & 1330 & 865 \\
& PS-PACH II & 1255 & 816 \\
& PS-1411 & 3088 & 2007 \\
& PS-ET & 1200 & 780 \\
& Mínimo & 589 & 383 \\
& Máximo & 3088 & 2007 \\
AqA & Médio & 1518 & 980 \\
\hline AqJ: Aqufer & VBET-05 & 1590 & 1034 \\
\hline
\end{tabular}

AqJ: Aquífero Jandaíra;.AqA: Aquífero Aluvial I

*Medições obtidas entre agosto de 2012 e janeiro de 2013, portanto representivas do período seco da região, conforme Figura 6. 


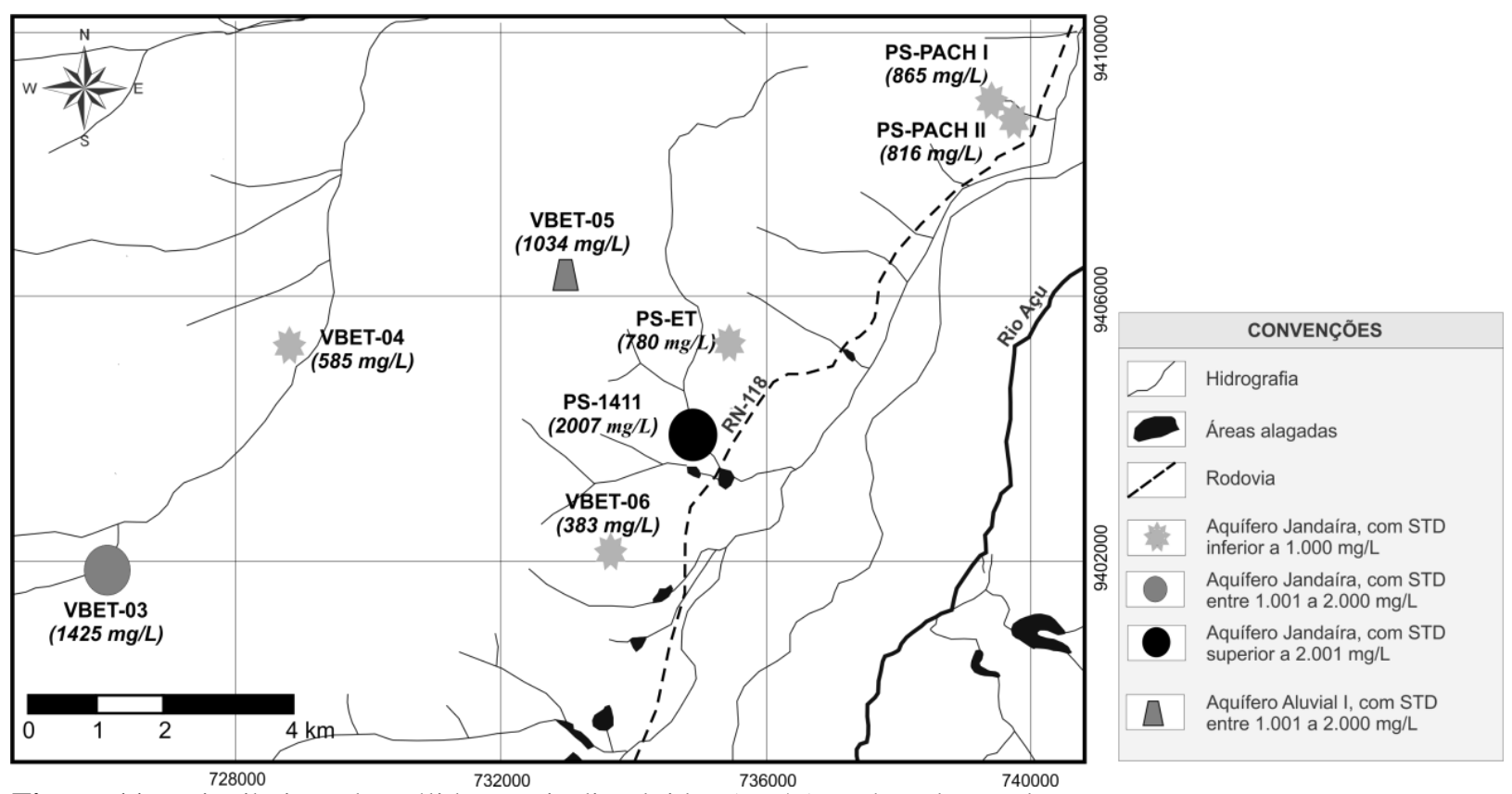

Figura 11 - Distribuição dos sólidos totais dissolvidos ( $\mathrm{mg} / \mathrm{L})$ na área de estudo

Figure 11 - Distribution of total dissolved solids $(\mathrm{mg} / \mathrm{L})$ in the studied area

No único poço no Aquífero Aluvial I, os sólidos totais dissolvidos apresentaram valores da ordem de $1034 \mathrm{mg} / \mathrm{L}$, sendo classificadas como águas ligeiramente salobras.

De acordo com a Portaria 2914 do MS (Brasil, 2011) que estabelece os padrões de potabilidade das águas, o valor máximo permitido para águas destinadas ao consumo humano é de $1000 \mathrm{mg} / \mathrm{L}$. Nesse contexto, apenas 2 (duas) amostras no Aquífero Jandaíra são consideradas impróprias para o consumo no âmbito estudado: os poços VBET-03 (1425 mg/L de STD) e PS1411 (2007 mg/L de STD). A única amostra obtida para o Aquífero Aluvial I apresentou 1034 $\mathrm{mg} / \mathrm{L}$ de STD, portanto, imprópria para o consumo humano.

O enquadramento das águas para sua utilização na irrigação foi realizado mediante os resultados de condutividade elétrica obtidos em campo. A salinidade das águas de irrigação pode afetar diretamente o rendimento das culturas.

De acordo com a classificação das águas para irrigação quanto ao risco de salinidade estabelecido pela UCCC-University of California Commitee of Consultants (Ayers e Westcot, 1991), as águas amostradas do Aquífero Jandaíra são enquadradas conforme apresentado na Tabela 3.

Observa-se que a maioria dos poços avaliados $(71,4 \%)$ são enquadrados na classe $\mathrm{C} 3$, com águas de elevada salinidade, que podem ser utilizadas apenas na irrigação de culturas com alta tolerância aos sais e mediante métodos de irrigação que mantêm o solo continuamente úmido.

\section{CONSIDERAÇÕES FINAIS}

A área estudada revela que o Aquífero Jandaíra, composto predominantemente por calcários, é a unidade aquífera rasa de maior importância no âmbito local. Trata-se de um aquífero livre, de natureza cárstico-fissural, que nos poços estudados apresentou profundidades entre 40,0 e 122,0 metros.

O Aquífero Aluvial I, também de caráter livre, mostra grandes variações nas espessuras litológicas e espessura saturada, as quais inclusive são desprezíveis em alguns setores, caracterizando que este aquífero se apresenta como de menor potencial para acumulação/armazenamento e explotação de águas subterrâneas, se comparado localmente ao Aquífero Jandaíra estudado.

Pontualmente fica caracterizada a interconexão hidráulica entre as unidades aquíferas, representando um único sistema aquífero. De maneira geral, o Aquífero Aluvial I compõe uma unidade de recepção e transferência de água de recarga para o Aquífero Jandaíra subjacente.

As águas avaliadas do Aquífero Jandaíra são classificadas como águas doces a ligeiramente salobras. Do ponto de vista de adequação de suas águas para o consumo humano e considerando apenas o parâmetro STD, estas podem ser consumidas pela população em alguns setores, sem 
prejuízo à saúde. Aproximadamente $71 \%$ das águas avaliadas apresentou STD inferior a 1000 $\mathrm{mg} / \mathrm{L}$, portanto dentro dos valores máximos per- mitidos pelos padrões de potabilidade para esse parâmetro.

Tabela 3 - Classificação das águas do Aquífero Jandaíra para irrigação quanto ao risco de salinidade Table 3 - Classification of the waters of the Jandaíra Aquifer for irrigation regarding salinity risk

\begin{tabular}{|c|c|c|c|}
\hline Ponto & $\mathrm{CE}(\mu \mathrm{s} / \mathrm{cm})$ & Classe de Salinic & dade conforme UCCC* \\
\hline- & - & $\begin{array}{l}\mathrm{C} 1 \\
(\mathrm{CE}<250 \\
\mu \mathrm{s} / \mathrm{cm})\end{array}$ & $\begin{array}{l}\text { Água de baixa salinidade. Pode ser usada para irrigação } \\
\text { da maioria das culturas, em quase todos os tipos de so- } \\
\text { los. }\end{array}$ \\
\hline VBET-06 & 589 & $\begin{array}{l}\text { C2 } \\
(\mathrm{CE} \text { entre } 250 \text { e } \\
750 \mu \mathrm{s} / \mathrm{cm})\end{array}$ & $\begin{array}{l}\text { Água de média salinidade. Pode ser usada sempre e } \\
\text { quando houver uma lixiviação moderada de sais. Em } \\
\text { quase todos os casos permitem o cultivo de plantas mo- } \\
\text { deradamente tolerante aos sais. }\end{array}$ \\
\hline VBET-04 & 900 & & \\
\hline VBET-03 & 2192 & & \\
\hline PS-PACH I & 1330 & $\begin{array}{l}\text { C3 } \\
\text { (CE entre } 750 \text { e } \\
2250 \mu \mathrm{s} / \mathrm{cm})\end{array}$ & $\begin{array}{l}\text { Água de alta salinidade. Não pode ser usada em solos } \\
\text { com drenagem deficiente. Deve ser utilizada na irrigação } \\
\text { de espécies vegetais de alta tolerância aos sais. Os riscos } \\
\text { apresentados podem ser amenizados quando do emprego } \\
\text { do método de irrigação mantendo o solo continuamente } \\
\text { úmido. }\end{array}$ \\
\hline
\end{tabular}

PS-ET

1200

\begin{tabular}{|c|c|c|c|}
\hline PS-1411 & 3088 & $\begin{array}{l}\text { C4 (CE >2250 } \\
\mu \mathrm{s} / \mathrm{cm})\end{array}$ & $\begin{array}{l}\text { Água de muito alta salinidade. Não é apropriada para } \\
\text { irrigação sob condições normais. Os solos devem ser } \\
\text { permeáveis, a drenagem adequada, devendo ser aplicada } \\
\text { água em excesso para se obter uma boa lixiviação de sais } \\
\text { e, mesmo assim devem ser explorados com culturas al- } \\
\text { tamente tolerantes aos sais. }\end{array}$ \\
\hline
\end{tabular}

*University of California Commitee of Consultants

A utilização dessas águas na irrigação deve ser vista com cautela, já que grande parte se mostrou restritiva para culturas com baixa tolerância a sais, de modo que o seu uso requer técnicas específicas de irrigação. Convém ressaltar que o uso inadequado dessas águas pode acarretar problemas de salinização dos solos.

Fica caracterizada a possibilidade de utilização do Aquífero Jandaíra no atendimento local às pequenas comunidades e/ou particulares de setores rurais circunvizinhos. A sua inserção de forma mais segura num processo de gestão de águas subterrâneas depende de estudos posteriores

\section{REFERÊNCIAS}

Amorim Júnior V.; Lima, O.A.L. Avaliação AYERS, R. S., WESTCOT, D. W. A qualidade da água na agricultura. Trad. Gheyi, H. R., Medeiros, J. F., DAMASCENO, F.V. Campina Grande: UFPB. 218p. (Estudos FAO: Irrigação e Drenagem, 29 revisado1). 1991. para reconhecimento do seu real potencial.

Recomenda-se a execução de estudos geofísicos para incrementar o conhecimento da estrutura hidrogeológica, a execução de testes de aquífero para obtenção de parâmetros hidrodinâmicos, melhor entendimento sobre a interconexão hidráulica/contribuição/recarga do Aquífero Aluvial I para o Aquífero Jandaíra e avaliação de reservas, bem como amostragem e análise química mais abrangente, incluindo parâmetros físicos e químicos visando uma caracterização mais eficaz da qualidade das águas.

BERTANI, R. T.; COSTA, I. G.; MATOS, R. M. D. Origem e Evolução de Bacias Sedimentares. Rio de Janeiro: PETROBRAS, 1990. 
BEZERRA, F. H. R.; AMARAL, R. F.; SILVA, F. O.; SOUSA, M. O. L.; FONSECA, V. P.; VIEIRA, M. M. Carta Geológica Folhas Macau SB.24-X-D-II e SB.24X-B-V. Escala 1:100.000. CPRM - Serviço Geológico do Brasil, 2009.

BRASIL. Ministério da Saúde. 2011. Portaria n 2914 de 12 de dezembro de 2011. Dispõe sobre os procedimentos de controle e de vigilância da qualidade da água para consumo humano e seu padrão de potabilidade.

DANTAS, E. P. Gravimetria e Sensoriamento Remoto: Uma Aplicação ao Estudo da Tectônica Recente entre Macau e São Bento do Norte (RN). Programa de Pós-Graduação em Geodinâmica e Geofísica da Universidade Federal do Rio Grande do Norte, Natal, Dissertação de Mestrado, 98 páginas, 1998.

DINIZ FILHO, J. B.; CARVALHO JÚNIOR, E. R.; STEIN, P.; MELO JUNIOR, G.; CARVALHO, M. F. B.; ROSÁRIO, F. F.; RIBEIRO FILHO, J. C.; CABRAL, N. M. T.; CARVALHO, A. K. N. Atributos e modelo hidrogeológico conceitual do aquífero carbonático raso em áreas da Bacia Potiguar, $\mathrm{RN}$ - Brasil. In: XV Congresso Brasileiro de Águas Subterrâneas, 2008, Natal. Anais... 2008.

EMBRAPA. Empresa Brasileira de Pesquisa Agropecuária. Brasil em Relevo. Monitoramento por Satélite. Campinas, 2005. Disponível em: $<$ http://www.relevobr.cnpm.embrapa.br>.

FEITOSA, F.A.C., FEITOSA, E.C., e MANOEL FILHO, J. Hidrogeologia, Conceitos e Aplicações. $3^{a}$ Edição. 2008.

GOLDSCHEIDER, N.; DREW, D. Methods in Karst Hydrogeology: IAH: International Contributions to Hydrogeology. Hardcover. 264 p. 2007.

HEM, J. D. Study and interpretation of the chemical characteristics of natural water. US Geological Survey water-supply. 1985

MAIA, R. P.; SOUSA, M. O. L.; BEZERRA, F. H. R.; NETO, P. X.; MOURA-LIMA, E. N.; SILVA, C. C. N.; SANTOS, R. D. A importância do controle tectônico para a Formação da paisagem cárstica na Bacia Potiguar, nordeste do Brasil. Revista Brasileira de Geomorfologia. v.13, n.4, p.451-463. 2012.
MANDEL, S.; SHIFTAN, Z. L. Groundwater Resources (Water pollution). Salt Lake City: Academic Press, 1981.

MATOS, R. M. D. Sistema de Riftes Cretáceos do Nordeste Brasileiro. PETROBRAS/DEPEX/DEBAR. Relatório Interno, 34p. 1987.

MCNEELY, R. N.; NEIMANIS, V. P.; DWYER, L. Water Quality Sourcebook. A Guide to Water Quality $\mathrm{Pa}$ rameters. Ottawa, Canadá. 89 p. 1979

MISTRETA, G. O Aquífero Jandaíra da Bacia Potiguar. Dissertação de Mestrado em Geociências. USP, São Paulo. 1984.

MOURA-LIMA, E. N.; SOUSA, M. O. L.; BEZERRA, F. H. R; AQUINO, M. A.; VIEIRA, M. M.; LIMA-FILHO, F. P.; FONSECA, V. P.; AMARAL, R. F. Sedimentação e deformação tectônica neogênicas e quaternárias no centro da Bacia Potiguar. Geologia USP, Série Científica, v. 10, n. 1, p. 15-28. 2010.

MOURA-LIMA, E. N.; SOUSA, M. O. L.; BEZERRA, F. H. R; CASTRO, D. L., DAMASCENA, R. V. V.; VIEIRA, M. M.; LEGRAND, J. M. Reativação Cenozoica do Sistema de Falhas de Afonso Bezerra, Bacia Potiguar. UNESP, Geociências, v. 30, n. 1, p. 77-93. 2011

NETO, P. X. Processamento e Interpretação de Dados 2E e 3D de GPR: Aplicações no Imageamento de Feições Kársticas e Estruturas de Dissolução no Campo de Petróleo de Fazenda Belém - CE. Natal, Rio Grande do Norte, Brasil, 2006. Tese (Doutoramento em Geodinâmica e Geofísica). Universidade Federal do Rio Grande do Norte.

SERHID. Secretaria de Recursos Hídricos do Estado do Rio Grande do Norte. Plano Estadual de Recursos Hídricos. Caracterização Hidrogeológica dos Aquíferos do Rio Grande do Norte. Natal: 1998.

STEIN, P. Hidrogeoquímica das Águas Subterrâneas da Bacia Sedimentar Potiguar/RN e Caracterização da Salinização do Aquífero Cárstico Jandaíra. Recife, Pernambuco, Brasil, 2013, 204 p. Tese (Doutoramento em Hidrogeologia). Universidade Federal de Pernambuco. 